\title{
Faktor-Faktor yang Mempengaruhi Keberlanjutan Ruang Terbuka Hijau di DKI Jakarta
}

\section{Factors Affecting the Sustainability of Green Open Space in DKI Jakarta}

\author{
Suryani $^{1, *}$, Pudji Muljono $^{2}$, Djoko Susanto $^{2}$, Sri Harijati $^{3}$
}

${ }^{1}$ Program Studi Agroteknologi, Fakultas Pertanian, Universitas Respati Indonesia, Jakarta 13890, Indonesia ${ }^{2}$ Departemen Sains Komunikasi dan Pengembangan Masyarakat, IPB University, Bogor 16680, Indonesia ${ }^{3}$ Departemen Agribisnis, Universitas Terbuka, Tangerang 15437, Indonesia

${ }^{*}$ E-mail korespondensi: suryani@urindo.ac.id

Diterima: 26 April 2021 | Disetujui: 14 September 2021 | Publikasi Online: 28 September 2021

\begin{abstract}
The quantity and quality of green open space (RTH) in big cities in Indonesia has decreased and resulted in environmental damage. The existence of green space is very much needed by the people of DKI Jakarta. However, the availability has not met the standards set by law, it is suspected that the capacity of RTH managers and the role of stakeholders in encouraging land use for RTH sustainability is not maximized. This study aims to analyze the level of sustainability of RTH and analyze the factors that influence the sustainability of RTH in DKI Jakarta. The research method uses quantitative data with survey methods and questionnaires as a data collection tool. The number of samples taken as many as 340 people for sub-districts and villages was selected by purposive sampling with the consideration that there are green alley activities for the sustainability of RTH. Data were collected from December 2019 to February 2020. The data were analyzed descriptively using SPSS 24 and inferential PLS 3. The results showed that the level of sustainability of RTH in DKI Jakarta was in the low category on economic, ecological, socio-cultural aspects and very low category for aesthetics. Stakeholder support has a positive and real impact on the sustainability of RTH which is reflected by the role of the government, community, media and extension workers. Manager capacity also has a positive and significant impact on the sustainability of $R T H$ which is reflected by technical, managerial and social capacities.
\end{abstract}

ABSTRACT

Keywords: Green open space, manager capacity, role of stakeholders, sustainability

\section{ABSTRAK}

Kuantitas dan kualitas Ruang Terbuka Hijau (RTH) pada kota-kota besar di Indonesia mengalami penurunan dan mengakibatkan rusaknya lingkungan hidup. Keberadaan RTH sangat dibutuhkan oleh masyarakat DKI Jakarta. Walau demikian ketersediaan belum memenuhi standar yang ditetapkan Undang-Undang, diduga kapasitas pengelola RTH dan peran pemangku kepentingan dalam mendorong pemanfaatan lahan untuk keberlanjutan RTH belum maksimal. Penelitian ini bertujuan menganalisis tingkat keberlanjutan RTH dan menganalisis faktor-faktor yang memengaruhi keberlanjutan RTH di DKI Jakarta. Metode penelitian menggunakan data kuantitatif dengan metode survei dan kuesioner sebagai alat pengumpul data. Jumlah sampel yang diambil sebanyak 340 orang untuk kecamatan dan kelurahan dipilih secara purposive sampling dengan pertimbangan terdapat kegiatan gang hijau untuk keberlanjutan RTH. Data dikumpulkan pada bulan Desember 2019 sampai Februari 2020. Data dianalisis secara deskriptif menggunakan SPSS 24 dan inferensial PLS 3. Hasil penelitian menunjukkan tingkat keberlanjutan RTH di DKI Jakarta berada dalam kategori rendah pada aspek ekonomi, ekologi, sosial budaya dan kategori sangat rendah untuk estetika. Dukungan stakeholder berpengaruh positif dan nyata terhadap keberlanjutan RTH yang direfleksikan oleh peran pemerintah, masyarakat, media dan penyuluh. Kapasitas pengelola juga berpengaruh positif dan nyata terhadap keberlanjutan RTH yang direfleksikan oleh kapasitas teknis, manajerial dan sosial.

Kata kunci: Ruang terbuka hijau, kapasitas pengelola ruang terbuka hijau, peran penyuluh/pemberdaya masyarakat kota, Keberlanjutan work, journal citation and DOI.

Published under Department of Communication and Community Development Science, IPB University and in association with Perhimpunan Ahli Penyuluhan Pembangunan Indonesia.

E-ISSN: 2442-4110 | P-ISSN: 1858-2664 


\section{PENDAHULUAN}

Provinsi DKI Jakarta merupakan wilayah di Indonesia yang paling kompleks dan pertumbuhan penduduknya terus meningkat sebesar 269 per hari atau sekitar 11 jiwa jam, sehingga sangat perlu didukung oleh pertumbuhan RTH untuk keharmonisan lingkungan alam dan sosial (Prakoso \& Herdiansyah, 2019). Penyediaan Ruang Terbuka Hijau (RTH) merupakan amanat dari UU No.26/2007 tentang Penataan Ruang yang disyaratkan proporsi luas RTH pada suatu kota minimum sebesar 30 persen dari luas wilayah kota yang dibagi menjadi RTH publik 20 persen dan RTH privat sebesar 10 persen. Pengertian RTH kawasan perkotaan adalah area memanjang atau jalur, yang penggunaannya lebih bersifat terbuka, tempat tumbuh tanaman (Permen PU No.05/2008) yang kegunaanya untuk memberikan keamanan, kenyamanan, kesejahteraan, dan keindahan wilayah perkotaan tersebut (Infokum \& Binbangkum, 2007). Perubahan ketersediaan RTH sering terjadi akan membawa dampak dan masalah baru seperti penggusuran dan tukar guling aset pemeritah dengan swasta. Menurut hasil penelitian Setyani et al. (2017) bahwa perubahan RTH dipengaruhi oleh ketersediaan luas lahan kosong di kota dan kesiapan SDM pengelola RTH.

Menurut Undang-Undang Nomor 26 tahun 2007 konsep keberlanjutan RTH adalah penataan ruang dilakukan dengan menjamin kelangsungan dan kelestarian lingkungan untuk kepentingan generasi yang akan datang. Manfaat RTH di wilayah perkotaan mendukung fungsi ekologi, ekonomi, sosial budaya, dan estetika (Permendagri No.1/2007). Ruang Terbuka Hijau juga menjadi elemen kunci lanskap perkotaan yang berkelanjutan dalam meningkatkan kualitas lingkungan, sarana interaksi sosial dan kualitas hidup masyarakatnya (Rojas, Páez, Barbosa, \& Carrasco, 2016). Namun, luas RTH sering berkurang karena adanya pelanggaran bangunan untuk tempat tinggal dan usaha. Upaya pemerintah untuk melakukan penertiban dan memodifikasi menjadi taman objek wisata (Armaeni, Suranata, Gde, \& Triswandana, 2017).

Pengelolaan RTH masih membutuhkan peran berbagai stakeholders terutama peran penyuluh perkotaan. Menurut (Lini, Hamzah, \& Abdullah, 2018) penyuluh perkotaan minimal memiliki empat peran utama, yiatu sebagai pembimbing, fasilitator, organisator dan dinamisator. Sebagai pembimbing penyuluh berusaha membimbing para kelompok untuk menjaga dinamika kelompok dalam mencapai tujuannya. Sebagai fasilitator penyuluh terus memberi fasilitas yang dibutuhkan para anggota kelompok. Sebagai organisator penyuluh mengupayakan petani dapat berorganisasi dengan baik dan memanfaatkannya untuk kemajuan bersama. Sebagai dinamisator penyuluh tersu membri semangat untuk dinamis dan trus maju dalam pengembangan efektifitas kelompok.

Penyediaan RTH penting untuk mensukseskan program Eco Cultural City yang menjadi cikal bakal terbentuknnya human settlement. Kota besar sebagai tempat kehidupan, terbentuknya human settlement menjadi kekuatan kemajuan masyarakat yang mandiri dan modern. Human settlement sebuah pemukiman yang didukung oleh elemen dasar permukiman yaitu: adanya rumah-rumah, jaringan prasarana, alam, manusia dan masyarakat (Susilowati, 2013).

Urban farming merupakan salah satu kegiatan dalam penerapan komsep Eco Cultural City. Hasil penelitian Ahmad Rifqi Fauzi \& Annisa Nur Ichniarsyah (2016) menunjukkan bahwa hambatan dalam pengembangan urban farming adalah partisipasi masyarakat rendah, penguasaan lahan pekarangan skala kecil, dan kurangnya dukungan pemerintah. Keberadaan ruang terbuka hijau berperan penting dalam menjaga kualitas kehidupan kota dengan unsur lingkungan alami. Konsep ekologi lanskap berupaya mewujudkan kota yang sehat banyak oksigen dan memperhatikan hubungan timbal balik antara kehidupan kota dengan lingkungan alaminya sesuai kondisi iklim tropis (Fuady, 2011). Menurut (Lestari et al., 2012) dan (Woltjer, 2014), bahwa RTH akan dapat berhasil jika sumberdaya manusia yang mengelola alam professional.

Hasil penelitian Setyani et al. (2017), masih kurangnya ketersediaan RTH berdasarkan jumlah penduduk ada hubungan signifikan dan positif dengan jumlah fasilitas, ekonomi dan jarak tempuh pada wilayah kota. Faktor yang berhubugan negatif adanya fasilitas pendidikan, fasilitas sosial, luas RTH sebelumnya proporsi lahan terbangun pada RTRW dan banyaknya jumlah penduduk terbaru. Berdasarkan hasil kajian RTH oleh Saputra and Ma'sum (2017) menunjukkan bahwa strategi untuk pemgembangan RTH berkelanjutan, karena ketersediaan lahan untuk RTH. Selain itu berdasarkan pengukuran SIG terjadi perubahan RTH dibandingkan luas eksistingnya (Wahyuningsih, 2018).

Penelitian Setiyawan dan Akbari (2021), menunjukkan bahwa penurunan RTH disebabkan oleh program pemberdayaan masyarakat di wilayah sekitar RTH menjadi tekanaan utama dalam pengembangan RTH yang berkelanjutan. Hasil penelitian Supratiwi (2018), bahwa kendala pengembangan RTH karena rendahnya pendanaan, lemahnya pengawasan, lemahnya penegakan hukum dan komitmen pemerintah kota yang masih 
kurang. Sehingga, perlu peningkatan partisipasi pihak swasta untuk membantu pemerintah dalam mengatasi permasalahan terkait pengembangan RTH.

Provinsi DKI Jakarta sampai tahun 2019 proporsi RTH belum sesuai yang diamanatkan oleh Undang-Undang Nomor 26 Tahun 2007. Permasalahanya adalah diduga masih rendahnya kapasitas sumber daya manusia sebagai pengelola RTH, kurangnya partisipasi masyarakat dan peran stakeholders seperti pemerintah, swasta dan Perguruan Tinggi dalam mendukung keberlanjutan program RTH belum maksimal. Selain itu terdapat kendala-kendala implementasi RTH yaitu: masih lemahnya pengawasan pada penggunaan lahan dan bangunan; harga tanah yang relatif mahal; peningkatan lahan-lahan terbangun; dan kurangnya sosialisasi kepada masyarakat mengenai arti penting RTH (Hendra Wijanto, 2017). Menurut Iswari (2014) pengembangan RTH di kota terkendala oleh terbatasnya anggaran, minimnya sarana dan prasarana. Sebagian besar hasil penelitian yang telah lalu tersebut masih kurang membahas tentang faktor-faktor keberlanjutan yang komprehensif, sehingga penelitian ini tertarik memenuhi beberapa vareabel yang belum diteliti tersebut. Berdasarkan latar belakang dan penelitian-penelitain terdahulu maka tujuan penelitian adalah: (1) menganalisis tingkat keberlanjutan Ruang Terbuka Hijau dan (2) menganalisis faktor-faktor yang memengaruhi keberlanjutan ruang Terbuka Hijau di DKI Jakarta.

\section{METODE PENELITIAN}

Penelitian didesain dengan pendekatan kuantitatif dengan metode survei. Penelitian dilakukan di 22 Kecamatan dan 29 Kelurahan di lima Kota Administrasi DKI Jakarta. Penentuan kecamatan dan kelurahan menggunakan metode purposive sampling berdasarkan wilayah mendapat program RTH. Pengambilan data lapangan dilaksanakan mulai bulan Desember 2019 sampai dengan bulan Februari 2020. Populasi penelitian sejumlah 2.236 responden, jumlah sampel ditentukan secara proporsional didapatkan 340 responden. Jenis data yang dikumpulkan meliputi data primer dan data sekunder. Data primer diperoleh melalui hasil pengamatan langsung di lapangan dan hasil wawancara dengan responden di lokasi penelitian.

Instrumen penelitian yang digunakan untuk pengumpulan data primer adalah kuesioner dan wawancara. Variabel independen dalam penelitian ini adalah (X1): karakteristik individu; (X2): kosmopolitan; (X3): stakeholders; (X4): partisipasi. Variabel dependen, yaitu: (Y1): kapasitas; dan (Y2): keberlanjutan. Indikator dari variabel eksogen (X1): karakteristik individu (X1.3; pendidikan non formal; X1.5: motivasi); (X2): kosmopolitan (X2.1: keluar wilayah; X2.3: keluar kelompok, X2.4: penggunaan media); (X3): stakeholders (X3.1: peran pemerintah; X3.3: peran masyarakat; X3.4: peran media; X3.5: peran penyuluh); X4: partisipasi (X4.1: merencanakan; X4.2: melaksanakan; X4.3: memanfaatkan hasil; X4.4: evaluasi). Indikator dari variabel endogen, yaitu: (Y1): kapasitas: (Y1.1: teknis, Y1.2: manajerial; dan Y1.3: sosial), (Y2): Keberlanjutan (Y2.1: ekonomi; Y2.2: ekologi; Y2.3: sosial budaya; dan Y2.4: estetika). Kuesioner yang disiapkan berisi pertanyaan yang merupakan penjabaran dari peubah penelitian. Data sekunder merupakan data hasil pengolahan dari sumber yang relevan sebagai pendukung data penelitian. Sumber data sekunder dari profil kota Jakarta, data Badan Pusat Statistik DKI Jakarta, laporan kajian dan hasil penelitian terdahulu yang relevan dengan penelitian.

Data sekunder yang dikumpulkan dalam penelitian ini adalah (1) Data demografi wilayah penelitian, meliputi kondisi fisik dan keadaan penduduk; (2) Dokumen kegiatan penyuluhan, meliputi program penyuluhan dan laporan penyuluhan; (3) Dokumen dari lembaga penyuluhan terkait dengan ketenagaan dan program penyuluhan di wilayah penelitian. Analisis data menggunakan uji statistik deskriptif dan inferensial. Uji statistik deskriptif menggunakan analisis program excel dan SPSS (Statistical Product and Service Solution) versi 24 dan analisis statistik inferensial menggunakan program Partial Least Square (PLS) 3. Pengujian hipotesis satu arah dilakukan dengan melihat tingkat signifikansi dari nilai koefisien path yang ditunjukkan oleh nilai t-statistik harus diatas 1.96 untuk alpha 5 persen (Cress Well, 2007). Berdasarkan hasil uji validitas menggunakan alat bantu program Statistical Product and Service Solutions (SPSS) versi 24, menunjukkan bahwa kuesioner layak digunakan lebih lanjut. Hal ini terlihat dari nilai $r$ hitung yang berkisar 0,381 sampai dengan 0,779, artinya nilai tersebut lebih besar dari 0,361 sesuai ketentuan. Kemudian nilai cronbachs alpha yang dihasilkan berkisar dari 0,509 sampai 0,879 menunjukkan lebih besar dari $r$ tabel $(0,361)$ (Arikunto S, 2010). 


\section{HASIL DAN PEMBAHASAN}

\section{Keberlanjutan Ruang Terbuka Hijau}

\section{Aspek Ekonomi}

Tabel 1. Tingkat keberlanjutan Ruang Terbuka Hijau (RTH)

\begin{tabular}{llcc}
\hline \multirow{2}{*}{ Tingkat Keberlanjutan } & \multicolumn{1}{c}{ Kategori } & \multicolumn{2}{c}{ Jumlah } \\
\cline { 3 - 4 } & & Orang (n) & Persentase (\%) \\
\hline Keberlanjutan Ekonomi & Sangat rendah (Skor 3-6) & 93 & 27,4 \\
& Rendah (Skor 7-8) & 145 & 42,6 \\
& Sedang (Skor 8-9) & 77 & 22,6 \\
& Tinggi (Skor 10-12) & 25 & 7,4 \\
Keberlanjutan Ekologi & Sangat rendah (Skor 4-7) & 52 & 15,3 \\
& Rendah (Skor 8-10) & 171 & 42,6 \\
& Sedang (Skor 11-13) & 81 & 23,8 \\
Keberlanjutan Sosial budaya & Tinggi (Skor 14-16) & 36 & 10,6 \\
& Sangat rendah (Skor 4-7) & 106 & 31,2 \\
& Rendah (Skor 8-10) & 132 & 38,8 \\
& Sedang (Skor 11-13) & 77 & 22,6 \\
Keberlanjutan Estetika & Tinggi (Skor 14-16) & 25 & 7,4 \\
& Sangat rendah (Skor 4-7) & 115 & 33,8 \\
& Rendah (Skor 8-10) & 100 & 29,4 \\
& Sedang (Skor 11-13) & 96 & 28,2 \\
& Tinggi (Skor 14-16) & 29 & 8,5 \\
\hline
\end{tabular}

Keterangan: $\mathrm{n}=340$

Tabel 1 memperlihatkan bahwa keberlanjutan RTH pada aspek ekonomi di DKI Jakarta persentase tertinggi 42.6 persen pada kategori rendah. Rendahnya keberlanjutan ekonomi di lokasi penelitian, disebabkan oleh hasil dari RTH belum mampu meningkatkan ekonomi keluarga dan hasill produksi baik sayuran maupun olahan masih terbatas untuk konsumsi sendiri. Selanjutnya masih rendahnya hasil budidaya tanaman karena pertanian bukan pekerjaan utama masyarakat DKI Jakarta. Akhirnya pada area RTH belum banyak menerima kunjungan wisatawan. Temuan di lokasi penelitian juga menunjukkan masih rendahnya keberlanjutan RTH aspek ekonomi disebabkan pengelola RTH belum maksimal dalam menjalin kerjasama dengan pihak swasta dalam pengembangan RTH yang dapat dikormersilkan dari segi estetika, misalnya dengan penataan RTH menjadi area rekreasi yang indah, sebagai upaya menarik wisatawan berkunjung ke area RTH dan membeli hasil produk dari tanaman.

Selaras dengan hasil penelitian Hidayani and Warsono (2017); Suryani, Muljono, Susanto, \& Harijati (2021) bahwa peran swasta masih rendah dalam pengembangan RTH, karena swasta selalu memikirkan untung dan ruginya untuk perusahaan. Selanjutnya pihak swasta juga lebih tertarik berinvestasi pada bidang yang memberi keuntungan cepat. Hasil penelitian Riyanto Suprayitno et al. (2011), menunjukkan bahwa masih rendahnya keberlanjutan ekonomi, disebabkan oleh masyarakat tidak menjadikan sumber utama pendapatan dari mengelola hutan, namun dijadikan pemasukan tambahan untuk rumah tangga. Menurut Mulyanie dan As'ari (2019), apabila ketersediaan RTH dimaksimalkan menjadi sumber produk tanaman hortikultura akan berdampak pada ekonomi mikro dari hasil menjual tanaman sayuran, buah, bunga dan herbal. Oleh karena itu, keberlanjtan RTH memerlukan dukungan dari pemangku kepentingan terkait yang netral dan fokus untuk mendukung tercapainya misi RTH (Samsudi, 2010). Hasil temuan Pratiwi, Tohjiwa, danMildawani (2020) bahwa RTH yang baik akan menguntungkan di masa sekarang, fisik, sosial dan yang akan datang. Implikasi dari hasil penelitian tersebut diatas bahwa program keberlanjtan RTH merupakan program multi sektor dan multi aspek secara terpadu agar cepat berhasil dan memiliki dampak yang luas bagi tingkat kesehatan dan kesejahteraan masyarakat kota.

\section{Aspek Ekologi}

Fungsi RTH di DKI Jakarta harus diarahkan untuk memperbaiki kualitas lingkungan yang sudah menurun kualitasnya sebagai upaya melindungi ekosistem kota. Tabel 1 memperlihatkan bahwa persentase keberlanjutan pada aspek ekologi RTH di Jakarta berada pada kategori rendah 42.6 persen. Maknanya bahwa, 
masyarakat di DKI Jakarta ada yang belum mempunyai kesadaran akan manfaat RTH untuk menjaga lingkungan perkotaan. Temuan di lokasi penelitian menunjukkan bahwa masyarakat kurang berpartisipasi menjaga kebersihan lingkungan di sekitar pemukiman, terbukti masih ada masyarakat yang membuang sampah sembarangan, sehingga sampah menyumbat di bantaran kali atau got-got sekitar tempat tinggalnya. Menumpuknya sampah di area RTH menimbulkan aroma yang kurang sedap dan pada saat musim penghujan beberapa wilayah di DKI Jakarta dilanda banjir, akibat saluran air tersumbat sampah.

Selaras dengan hasil penelitian Lestari et al. (2012); Suryani, Muljono, Susanto, \& Harijati (2021) bahwa rendahnya keberlanjutan RTH pada aspek ekologi karena kesadaran masyarakat dalam melestarikan lingkungan dengan menjaga kebersihan pemukiman masih kurang dan area RTH peruntukkanya untuk fungsi lain. Menurut hasil penelitian Mulyanie dan As'ari (2019), bahwa ketersediaan RTH di kota pada fungsi ekologis menghasilkan udara yang segar, tanah menjadi subur dan meredam suara bising karena adanya pohon yang ditanam di pemukiman. Selain itu, temuan terbaru oleh Putra dan Roosandriantini (2021) RTH konsep vertikal sangat sesuai dengan lingkungan gedung perkotaan dan memberi nilai tambah program green building.

\section{Aspek Sosial Budaya}

Manfaat dari RTH berkelanjutan bagi masyarakat di perkotaan adalah terbangunnya hubungan sosial antar warga yang harmonis dan menjadi wahana interaksi kegiatan di perkotaan. Merujuk Tabel 1 bahwa keberlanjutan RTH aspek sosial budaya RTH di Jakarta persentase tertinggi adalah 38.8 persen pada kategori rendah. Temuan di lokasi penelitian menunjukkan, gang hijau area RTH belum dimanfaatkan secara maksimal oleh masyarakat. Disamping itu ketersediaan RTH belum memengaruhi penurunan terjadinya konflik sosial di masyarakat, karena area RTH masih sebatas untuk interaksi dengan tetangga di sekitar pemukiman. Selanjutnya kendala pengembangan RTH sebagai sarana interaksi masyarakat pemukiman di DKI Jakarta adalah komunikasi dengan stakeholders masih kurang bersinergi, oleh sebab itu fasilitas yang ada di area RTH belum memenuhi kebutuhan untuk aktivitas masyarakat di sekitarnya.

Penelitian Susilowati (2017) menunjukkan bahwa fungsi RTH adalah fungsi sosial budaya dan keberlanjutan RTH memerlukan dukungan dari pemangku kepentingan yang komprehensif dalam memfasilitasi aktivitas masyarakat agar harmonis. Peryataan diperkuat hasill penelitian (Medeiros \& Zwet, 2020), bahwa pembangunan kota berkelanjutan harus ada keterlibatan aktif warga negara dan pemangku kepentingan. Bahkan hasil riset Triana, Aspar, dan Jumarni (2020) memberi insentif terhadap pengenaan pajak property (PBB perdesaan/perkotaan) efektif meningkatkan peran stakeholders terhadap RTH dan partisipasi masyarakat terhadap RTH sebesar 40\% saja. Implikasinya bahwa kombinasi program RTH perlu memadukan program top down dan bottom up, sehingga pada tataran lapangan dapat saling menjaga dan memiliki sebagai aset kepentingan bersama. Partisipasi masyarakat yang tinggal di sekitar lokasi RTH perlu ditingkatkan agar mau terlibat dalam menjaga lingkungan dan menjamin keberlanjutan.

\section{Aspek Estetika}

Fungsi estetika di wilayah perkotaan dapat meningkatkan citra kota dari nilai keindahan dan kenyamanan kawasan kota dengan ketersediaan tanaman yang beraneka warna, maka lingkungan menjadi terlihat indah dan asri. Walau demikian, masyarakat di DKI Jakarta masih ada yang belum berpartisipasi menjaga lingkungan di sekitar pemukiman tempat tinggalnya. Berdasarkan Tabel 1 memperlihatkan bahwa keberlanjutan RTH pada aspek estetika persentase tertinggi 33.8 persen pada kategori sangat rendah. Sangat rendahnya nilai keberlanjutan aspek estetika, karena masyarakat DKI Jakarta kurang memanfaatkan gang hijau sebagai area RTH di sekitar pemukiman untuk budidaya tanaman hortikultura yang direkomendasikan oleh Dinas Ketahanan Pangan, Kelautan dan Pertanian DKI Jakarta. Rekomensasi penataan tanaman yang rapi di gang hijau area RTH bertujuan menjaga lingkungan dan menarik wisatawan untuk berkunjung. Temuan di lokasi penelitian menunjukkan, masih banyak lingkungan pemukiman di sekitar gang hijau area RTH tidak tertata rapi, bahkan cenderung terlihat kumuh.

Hasil penelitian Suryani, Muljono, Susanto, \& Harijati, (2021) keberlanjutan RTH estetika di DKI Jakarta pada kategori sangat rendah karena kapasitas pengelola RTH dalam budidaya tanaman kurang dan keterlibatan masyarakat dalam memperindah area RTH di sekitar pemukiman belum maksimal. Selanjutnya ketersediaan lahan yang mereka miliki sempit, menjadi alasan masyarakat tidak menanam tanaman hortikultura di sekitar tempat tinggalnya. Pada beberapa wilayah penelitian terlihat gang hijau sebagai area RTH digunakan sebagai tempat parkir kendaraan pribadi. Temuan ini sesuai hasil penelitian Mulyanie dan As'ari (2019) bahwa masih rendahnya jumlah kunjungan wisatawan pada area RTH perkotaan, karena penataan tanaman tidak rapi dan 
kurang asri lingkungan wilayahnya. Implikasinya, RTH perlu di bangun dengan rancangan menyatu dengan alam dan sosial budaya masyarakat serta tidak bertentangan dnegan kearifan lokal warga setempat agar mudah diterima dan menjadi bagian penting untuk berbagai acara yang kental dengan sosial, adat dan budaya masyarakat sekitar RTH.

Faktor-Faktor yang Memengaruhi Keberlanjutan Ruang Terbuka Hijau di Jakarta

Tabel 2. Nilai signifikansi peubah laten keberlanjutan program Ruang Terbuka Hijau (RTH)

\begin{tabular}{clccc}
\hline No. & \multicolumn{1}{c}{ Matriks Pengaruh Peubah Laten } & Koefisien Jalur & T- Hitung & Signifikansi \\
\hline 1. & Karakteristik Individu => Keberlanjutan & 0.081 & 1.385 & Tidak Sig \\
2. & Kosmopolitan => Keberlanjutan & 0.077 & 0.813 & Tidak Sig \\
3. & Dukungan stakeholder => Keberlanjutan & 0.178 & 2.707 & Signifikan \\
4. & Tingkat Partisipasi => Keberlanjutan & -0.002 & 0.023 & Tidak Sig \\
5. & Kapasitas Pengelola RTH => Keberlanjutan & 0.261 & 4.014 & Signifikan \\
\hline
\end{tabular}

Keterangan: nilai t-hitung $>$ nilai $\mathrm{t}$-tabel(1.96) $=$ signifikan, $\alpha=5$ persenmode

Analisis Partial Least Square digunakan untuk mengetahui pengaruh karakteristik individu, tingkat kekosmopolitan, tingkat dukungan stakeholders dan tingkat partisipasi terhadap keberlanjutan RTH di DKI Jakarta. Pada tahap pertama dilakukan analisis first order confirmatori factor analysis (CFA). Tahap kedua menggunakan analisis model PLS untuk pengujian signifikansi hipotesis menggunakan proses bootstrapping. Pada analisis iterasi algoritma dilakukan beberapa kali, karena saat pertama kali dilakukan terdapat beberapa indikator yang memiliki nilai loading faktor dibawah 0.5 yang menunjukkan bahwa indikator-indikator tersebut tidak valid dan tidak reliabel. Maknanya bahwa indikator tersebut tidak merefleksikan masing-masing peubah laten, sehingga harus dikeluarkan dari model. Temuan ini selaras dengan hasil penelitian Imas Gandasari, Hotimah, dan Miarsyah (2021) bahwa keindahan dan kenyamanan dari RTH memiliki manfaat jangka panjang sebagai tanaman obat, penyerap udara kotor, dan melestarikan ragam flora dan fauna.

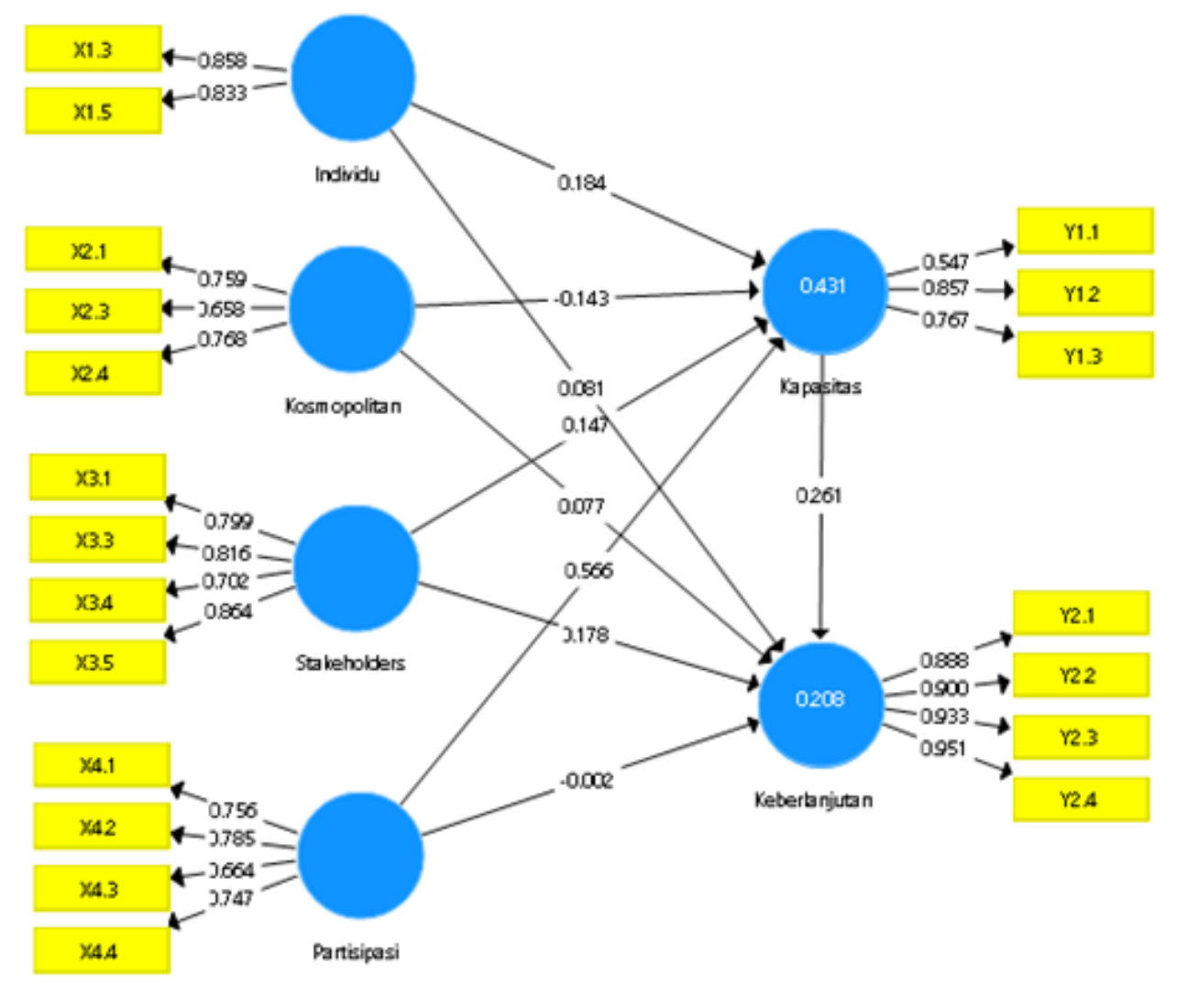

Gambar 1. Model pengukuran (outer model)

Hasil analisis Partial Least Square (PLS) menunjukkan terdapat faktor-faktor yang memengaruhi keberlanjutan RTH di DKI Jakarta. Persamaan model struktural adalah Y2 $=0.178 X 3+0.261$ Y $1+0.792$. Nilai R2 sebesar 0.208 yang artinya 20.8 persen keberlanjutan RTH dipengaruhi oleh faktor-faktor yang diteliti 
dalam penelitian ini, sedangkan 79.2 persen dipengaruhi oleh faktor lain diluar yang diteliti. Berdasarkan pada nilai R2 maka model yang dihasilkan berada pada kategori lemah. Hasil loading menunjukkan bahwa keseluruhan indikator sudah merefleksikan keberlanjutan pada aspek ekonomi, ekologi, sosial budaya dan estetika.

Tingkat dukungan stakeholder berpengaruh positif dan nyata terhadap keberlanjutan RTH di DKI Jakarta. Tingkat dukungan stakeholder direfleksikan oleh peran pemerintah, media, masyarakat dan penyuluh. Semakin tinggi tingkat dukungan pemerintah, masyarakat, media dan penyuluh maka keberlanjutan RTH di DKI Jakarta menjadi meningkat. Peran penyuluh perkotaan berperan penting dan memiliki makna strategis dalam mengawal keberhasilan program RTH. Temuan ini sangat sesuai dengan hasil penelitian (Sudibyo, Bakhtiar, \& Hasanah, 2019) bahwa ada hubungan yang positif antara karakteristik sosial penyuluh dengan tugas pokoknya sebagai penyuluh perkotaan di wilayah Batu Malang. Selain itu hasil penelitian (Aslamia, Mardin, \& Hamzah, 2017) menyatakan penyuluh perkotaan sudah berperan baik sebagai fasilitator, pengembangan organisasi,dan pengembangan kelompok tani perkotaaan sebagai wahana belajar, kerjasama dan unit produksi usahatani. Peran Penyuluh perkotaan disini kuramng optimal dalam pencarian informasi dan inovasi teknologi terkini.

Tingkat kapasitas pengelola RTH berpengaruh positif dan nyata terhadap keberlanjutan RTH di DKI Jakarta. Kapasitas pengelola RTH direfleksikan oleh kapasitas teknis, manajerial dan sosial. Semakin tinggi kapasitas pengelola RTH maka akan semakin meningkat keberlanjutan RTH. Temuan ini sesuai dengan hasil penelitian Susilowati (2017) yang menunjukkan bahwa dalam pengembangan RTH, diarahkan pada harmonisasi alam dan sosial dengan optimalisasi lahan melalui pot-pot tempat hidup berbagai tanaman secara lestari. Penelitian Prakoso dan Herdiansyah (2019), menunjukkan bahwa peningkatan partisipasi masyarakat dan penguatan regulasi yang dilaksanakan dengan konsisten menjadi syarat tercapainya luasan RTH 30 persen di DKI Jakarta. Senada dengan hasil penelitian Cahya, Widyawati, dan Ayodhia (2016) bahwa ketersediaan RTH di Kota yang masih minim dan kondisi masih kurang ideal perlu upaya kerja keras multi stakeholders untuk mewujudkan RTH lestari berkelanjutan.

\section{KESIMPULAN}

Kesimpulan dari penelitian ini adalah tingkat keberlanjutan RTH di DKI Jakarta berada pada kategori rendah pada aspek ekonomi, ekologi, sosial budaya dan kategori sangat rendah pada aspek estetika. Peran penyuluh perkotaan berperan penting dan memiliki makna strategis dalam mengawal keberhasilan program RTH di DKI Jakarta. Faktor-faktor yang memengaruhi keberlanjutan RTH di DKI Jakarta adalah tingkat dukungan stakeholders yang direfleksikan oleh peran pemerintah, media, masyarakat dan penyuluh. Pada tingkat kapasitas masyarakat aspek teknis, manajerial dan sosial berpengaruh positif terhadap keberlanjutan ruang terbuka hijau.

\section{DAFTAR PUSTAKA}

Anonim. Peraturan Menteri Dalam Negeri No. 1 Tahun 2007 tentang Penataan Ruang Terbuka Hijau Ruang Kawasan Perkotaan.

Anonim. Undang-Undang Republik Indonesia Nomor 26 Tahun 2007 tentang Penataan Ruang.

Anonim. Peraturan Menteri Pekerjaan Umum No.05/PRT/M/2008 tentang Pedoman Penyediaan dan Pemanfaatan Ruang Terbuka Hijau di Kawasan Perkotaan.Menteri Pekerjaan Umum. Jakarta.

Ahmad Rifqi Fauzi1)*,Annisa Nur Ichniarsyah1), H. A. (2016). Urban Agricuture : Urgency, Role, and Best Practice. Jurnal Agroteknologi, 10(1), 49-62.

Arikunto S. (2010). Prosedur Penelitian; Suatu Pendekatan Praktek. Jakarta: PT Rineka Cipta.

Armaeni, N. K., Suranata, P. G., Gde, I. W., \& Triswandana, E. (2017). Pemberdayaan Obyek Guna Lahan Di Kawasan Desa Sanur Sebagai Alternatif Ruang Terbuka Hijau ( RTH ) Kota Denpasar. 2-7.

Aslamia, Mardin, \& Hamzah, A. (2017). Peran Penyuluh Pertanian Dalam Pengembangan Kelompok Tani Di Kelurahan Matabubu Kecamatan Poasia Kota Kendari. Jurnal Ilmiah Membangun Desa Dan Pertanian, 2(1), 6-9. Retrieved from http://ojs.uho.ac.id/index.php/JIMDPdoi:http://dx.doi.org/10.33772/ jimdp.v2i1.6650

Cahya, D. L., Widyawati, L. F., \& Ayodhia, F. W. (2016). Evaluasi ketersediaan ruang terbuka hijau di Kota Bekasi. Jurnal Planesa, 7(1), 1-9. 
Cress Well. (2007). Qualitative Inquiry and Research Design: Choosing among Five Approaches.Choosing among Five Approaches. housand Oaks, CA: Sage.

Fuady, M. (2011). Ruang terbuka hijau ekologis sebagai penyedia oksigen dan penyimpan air untuk kota banda aceh. (2008).

Hendra Wijanto, R. K. H. (2017). Implementasi Kebijakan RTH DI KOTA ADMINITRASI JAKARTA UTARA PROVINSI DKI JAKARTA. Jurnal Ilmu Adminitrasi Publik, 2(1), 32-42.

Hidayani, H., \& Warsono, H. (2017). Analisis Kemitraan dalam Pengembangan Ruang Terbuka Hijau (RTH) di Kota Semarang. Journal Of Public Policy And Management Review, 6(2), 1-13.

Imas Gandasari, Hotimah, O., \& Miarsyah, M. (2021). Pemanfaatan Ruang Terbuka Kampus Sebagai Potensi Menjaga Lingkungan. Jurnal Green Growth Dan Manajemen Lingkungan, 9(2), 71-85. https://doi.org/10.21009/jgg.092.04

Infokum, S., \& Binbangkum, D. (2007). Permen No.01-2007. 1-8.

Iswari, A. N. (2014). Strategi Dinas Kebersihan dan Pertamanan Kota Surabaya dalam Pengelolaan Ruang Terbuka Hijau (RTH) untuk Mewujudkan Pembangunan Berkelanjutan dan Berwawasan Lingkungan. Kebijakan Dan Manajemen Publik, 1(1), 1-9. Retrieved from http://repository.unair.ac.id/16213/

Lestari, S. P., Noor, I., Ribawanto, H., Publik, J. A., Administrasi, F. I., \& Brawijaya, U. (2012). DALAM UPAYA MEWUJUDKAN SUSTAINABLE CITY ( Studi Pada Masterplan Pengembangan RTH Tahun 2012-2032 di Kabupaten Nganjuk ). 2(3), 381-387.

Lini, L., Hamzah, A., \& Abdullah, S. (2018). Peranan Penyuluh Pertanian Dalam Pengembangan Kelompok Tani Di Kelurahan Benua Nirae Kecamatan Abeli Kota Kendari. Jurnal Ilmiah Membangun Desa Dan Pertanian, 3(5), 128-132.

Mulyanie, E., \& As'ari, R. (2019). Fungsi Edukasi Ruang Terbuka Hijau Taman Kota Tasikmalaya. 338-345.

Prakoso, P., \& Herdiansyah, H. (2019). Analisis Implementasi 30\% Ruang Terbuka Hijau Di Dki Jakarta. Majalah Ilmiah Globe, 21(1), 17. https://doi.org/10.24895/mig.2019.21-1.869

Pratiwi, L. Y., Tohjiwa, A. D., \& Mildawani, I. (2020). Produksi Ruang Terbuka Hijau Publik Taman Terpadu. Lanskap Indonesia, 12(2), 63-72.

Putra, H. A., \& Roosandriantini, J. (2021). Ketersediaan dan Pemanfaatan Ruang Terbuka Hijau di Kampus UKDC Surabaya Availability and Utilization of Green Open Space at UKDC Surabaya Campus. Arsitektura, 19(1), 1-12. Retrieved from https://jurnal.uns.ac.id/Arsitektura/article/view/44374

Riyanto Suprayitno, A., Sumardjo, S., S. Gani, D., \& Ginting Sugihen, B. (2011). MODEL PENINGKATAN PARTISIPASI PETANI SEKITAR HUTAN DALAM PENGELOLAAN HUTAN KEMIRI RAKYAT: Kasus Pengelolaan Hutan Kemiri Kawasan Pegunungan Bulusaraung Kabupaten Maros Provinsi Sulawesi Selatan. Jurnal Penelitian Sosial Dan Ekonomi Kehutanan, 8(3), 176-195. https://doi.org/10.20886/jsek.2011.8.3.176-195

Rojas, C., Páez, A., Barbosa, O., \& Carrasco, J. (2016). Accessibility to urban green spaces in Chilean cities using adaptive thresholds. Journal of Transport Geography, 57(December), 227-240. https://doi.org/10.1016/j.jtrangeo.2016.10.012

Samsudi. (2010). Ruang Terbuka Hijau Kebutuhan Tata Ruang Perkotaan Kota Surakarta. Journal of Rural and Development, Vol. 1(No. 1), Hal. 11-19.

Saputra, W., \& Ma'sum, F. R. (2017). Perencanaan Ruang Terbuka Hijau (RTH) pada Kawasan Kelurahan Pampang Kota Makassar. D007-D010. https://doi.org/10.32315/ti.6.d007

Setiyawan, N., \& Akbari, T. (2021). Analisis Proyeksi Perubahan Ruang Terbuka Hijau Publik Di Kota Cilegon Pada Tahun 2025. JURNALIS: Jurnal Lingkungan, 4(1), 70-79. Retrieved from http://ejournal.lppm-unbaja.ac.id/index.php/jls/article/view/1215

Setyani, W., Risma, S., Sitorus, P., \& Panuju, R. (2017). Analisis Ruang Terbuka Hijau dan Kecukupannya di Kota Depok An Analysis of Greenery Open Space and Its Adequacy in Depok City. Buletin Tanah Dan Lahan, 1(1), 121-127.

Suryani, Muljono, P., Susanto, D., \& Harijati, S. (2021). Factors Affecting the Capacity of Green Gang Managers in the Utilization of Yards for Green Open Space in Jakarta. 4(2), 149-162.

Sudibyo, R. P., Bakhtiar, A., \& Hasanah, M. A. (2019). Hubungan Karakteristik Sosial Ekonomi Penyuluh dengan Pelaksanaan Tugas Pokok Penyuluh Pertanian di Kota Batu. Jurnal Ekonomi Pertanian Dan Agribisnis, 3(4), 710-719. https://doi.org/10.21776/ub.jepa.2019.003.04.6 
Supratiwi, S. (2019). Studi ruang terbuka hijau dalam kebijakan pengelolaan lingkungan hidup Pemerintah Kota Semarang. Jurnal Ilmiah Ilmu Pemerintahan, 3(2), 89. https://doi.org/10.14710/jiip.v3i2.3878

Susilowati, I. (2017). Konsep Pengembangan Ruang Terbuka Hijau ( RTH ) pada Permukiman Kepadatan Tinggi. Jurnal Pembangungan Wilayah Dan Kota, 9(4), 429-438.

Triana, D., Aspar, \& Jumarni. (2020). Strategi Peningkatan Partisipasi Masyarakat dalam Pengembangan Ruang Terbuka Hijau di Kota Makassar. Jurnal Lanskap Indonesia, 11(2), 43-47. https://doi.org/ 10.29244/jli.v11i2.22116

Wahyuningsih, H. (2018). Perhitungan Ruang Terbuka Hijau Perkotaan Jenis Publik (Studi Kasus : Kota Surakarta). Jurnal Arsitektur Dan Perencanaan (JUARA), 1(1), 106-115. https://doi.org/10.31101/juara.

v1i1.368

Woltjer, J. (2014). Jurnal Perencanaan Wilayah dan Kota. Jurnal Perencanaan Wilayah Dan Kota, 25(1), 1 16. https://doi.org/10.5614/jpwk.2014.25.1.1 